\title{
Correction of water vapor absorption for aerosol remote sensing with ceilometers
}

\author{
M. Wiegner and J. Gasteiger \\ Ludwig-Maximilians-Universität (LMU), Meteorologisches Institut, Theresienstraße 37, 80333 Munich, Germany \\ Correspondence to: M. Wiegner (m.wiegner@lmu.de)
}

Received: 23 April 2015 - Published in Atmos. Meas. Tech. Discuss.: 25 June 2015

Revised: 16 September 2015 - Accepted: 18 September 2015 - Published: 30 September 2015

\begin{abstract}
In recent years attention was increasingly paid to backscatter profiles of ceilometers as a new source of aerosol information. Several case studies have shown that - although originally intended for cloud detection only - ceilometers can provide the planetary boundary layer height and even quantitative information such as the aerosol backscatter coefficient $\beta_{p}$, provided that the signals have been calibrated. It is expected that the retrieval of aerosol parameters will become widespread as the number of ceilometers is steadily increasing, and continuous and unattended operation is provided. In this context however one should be aware of the fact that the majority of ceilometers provides signals that are influenced by atmospheric water vapor. As a consequence, profiles of aerosol parameters can only be retrieved if water vapor absorption is taken into account. In this paper we describe the influence of water vapor absorption on ceilometer signals at wavelengths around $\lambda=910 \mathrm{~nm}$. Spectrally high-resolved absorption coefficients are calculated from HITRAN on the basis of realistic emission spectra of ceilometers. These results are used as a reference to develop a methodology ("WAPL") for routine and near-real time corrections of the water vapor influence. Comparison of WAPL with the reference demonstrates its very high accuracy. Extensive studies with simulations based on measurements reveal that the error when water vapor absorption is ignored in the $\beta_{p}$-retrieval can be in the order of $20 \%$ for mid-latitudes and more than $50 \%$ for the tropics. It is concluded that the emission spectrum of the laser source should be provided by the manufacturer to increase the accuracy of WAPL, and that $910 \mathrm{~nm}$ is better suited than $905 \mathrm{~nm}$. With WAPL systematic errors can be avoided, that would exceed the inherent errors of the Klett solutions by far.
\end{abstract}

\section{Introduction}

In the last few years a large number of autonomous singlewavelength backscatter lidars, so called ceilometers, has been installed. Several ceilometer networks are operated by national weather services on a $24 / 7$ basis (e.g. Hirsikko et al., 2014). The number of such systems is rapidly growing and is assumed to be a few thousand, but only data of approximately 200 ceilometers are currently available online. Many ceilometers only retrieve cloud base heights according to their original design, however, in the last years more attention has been paid to the potential of ceilometers for aerosol-related retrievals: studies were devoted to the validation of transport models (e.g. Emeis et al., 2011; Wiegner et al., 2012) and to the assessment of the mixing layer height (e.g. Eresmaa et al., 2006; Münkel et al., 2007; Haeffelin et al., 2011) taking advantage from the fact that aerosols are a good tracer for mixing processes in the troposphere. These studies are often based on the exploitation of the ceilometer signal rather than on quantitative physical parameters. Though there are differences in the mathematical details of the analysis, basically these algorithms use the gradient of the ceilometer signal in one way or another. Typically, the time resolution of "raw" data is in the order of 15-30 s and the spatial resolution is in the range of $10-15 \mathrm{~m}$ up to a height of 7.5 or $15 \mathrm{~km}$ depending on the ceilometer type and its settings.

Being aware of the significance of aerosols for radiation, cloud physics and air quality, the discussion recently came up if optical properties can be derived quantitatively from ceilometers. If so, ceilometer networks might help to fill observational gaps; this information could be of benefit partic- 
ularly taking into account that aerosols are highly variable in time and space. As a consequence, recently first attempts were made to retrieve aerosol optical properties. Wiegner et al. (2014) show that the backscatter coefficient $\beta_{p}$ is the only parameter that can be determined accurately enough. Further quantities, such as the aerosol extinction coefficient $\alpha_{p}$ are prone to considerable errors if there is no additional information available, e.g., the magnitude of the lidar ratio $S_{p}$. Nevertheless, it is expected that in future backscatter coefficients can be quite useful for data assimilation and the validation of chemistry transport models, and for some kind of interpolation between the limited number of sophisticated research lidars. In particular it should be emphasized that, as $\beta_{p}$ is an absolute number, retrievals of ceilometer measurements at different sites and with different technical specifications can be jointly exploited; a pre-requisite to take full advantage of the networks.

Ceilometers typically are working in the near IR, either at $1064 \mathrm{~nm}$ (e.g., Jenoptik, Lufft) or at $905-910 \mathrm{~nm}$ (e.g., Vaisala, Eliasson, Campbell). Both wavelengths are in a spectral range where aerosol scattering is clearly dominating scattering by air molecules (Rayleigh scattering). This facilitates the detection of aerosol layers but raises problems of the signal calibration that is required to derive $\beta_{p}$. The main difference between the two wavelengths is however water vapor absorption: between 900 and $930 \mathrm{~nm}$ a strong absorption band exists whereas there is no absorption at $1064 \mathrm{~nm}$. This fact does not play a significant role when mixing layer heights are determined, however, water vapor absorption must be considered when profiles of $\beta_{p}$ shall be derived. This is, e.g., true for most of the frequently used Vaisala ceilometers (CT25k, CL31, CL51).

To our knowledge, Markowicz et al. (2008) were the first who corrected signals of a Vaisala CT25k-ceilometer for water vapor before deriving aerosol optical properties. This was done for measurements in the framework of the United Arab Emirates Unified Aerosol Experiment (UAE ${ }^{2}$ ) in 2004. Sundström et al. (2009) evaluating CL31 measurements from 2005 in Helsinki, restrict themselves to cases when they assumed that water vapor absorption can be neglected. The same assumption was made by Jin et al. (2015) using CL51 data. Madonna et al. (2015) mentioned water vapor absorption when they compared ceilometers of Jenoptik (CHM15k), Vaisala (CT25k) and Campbell (CS135s) but did not consider it quantitatively. In comparison with aerosol backscatter in the boundary layer derived from lidar and CL31 measurements (McKendry et al., 2009; Tsaknakis et al., 2011) or from different ceilometers (Haeffelin et al., 2011), water vapor absorption was not considered, which is not critical as long as only mixing layer heights (e.g. Leroyer et al., 2013; Young and Whiteman, 2015) or cloud base heights (e.g. Martucci et al., 2010) are determined. Emeis et al. (2007) avoided the problem by using a Vaisala LD40 ceilometer working at $855 \mathrm{~nm}$ instead of the standard Vaisala systems. Wiegner et al. (2014) discussed the problem in a general way on the basis of simulated signals. They pointed out that the unknown emission spectrum of the diode laser and the unknown water vapor distribution can introduce significant errors, and that at least an approximative correction should be applied. However, a systematic and thorough study of the influence of water vapor absorption on aerosol retrievals was beyond the scope of that paper. In this paper we want to give further insight into this topic and provide a methodology that can routinely be applied to real measurements.

In the following section we give a short outline of different solutions of the lidar equation applicable in case of water vapor absorption. The sensitivity to atmospheric and instrumental parameters is investigated in a general way by means of high spectral resolution calculations of absorption on the basis of standard atmospheres. This constitutes the basis to develop a methodology (henceforward referred to as WAPL) for routine evaluation of ceilometer data; a detailed discussion is provided in Sect. 4. Section 5 includes a case study based on simulations and real measurements to demonstrate the basic features of WAPL, and a robust estimate of the order of magnitude of the systematic error of $\beta_{p}$ when absorption is neglected. A summary and future needs to improve aerosol retrievals based on ceilometer measurements conclude the paper.

\section{Theoretical outline}

\subsection{Solution for the backscatter coefficient}

For aerosol remote sensing by means of a backscatter lidar elastic scattering is considered, i.e., the emitted and received wavelengths $\lambda$ are the same, and the emitted spectrum is "narrow". Thus, the lidar Eq. (1) is normally treated as "monochromatic", i.e., no wavelength-dependence of the optical properties is considered and the wavelength is not explicitly included:

$P(z)=C_{L} \frac{\beta(z)}{z^{2}} T_{\mathrm{p}}^{2}(z) T_{\mathrm{m}}^{2}(z) T_{\mathrm{w}, \mathrm{eff}}^{2}(z)$.

The lidar signal $P$ is written as a function of height $z$ assuming a vertically looking ceilometer. On the right hand side the transmissions of air molecules (subscript $\mathrm{m}$ ) and particles (subscript p),

$T_{i}=\exp \left\{-\int_{0}^{z} \alpha_{i}\left(z^{\prime}\right) \mathrm{d} z^{\prime}\right\}$ with $i \in\{m, p\}$,

and the transmission of water vapor (subscript $w$ ) that is obligatory if wavelengths around $910 \mathrm{~nm}$ are considered. In view of the fact that the emission spectrum of a ceilometer can be much broader than the line widths within an absorption band, an effective water vapor transmission $T_{\mathrm{w}, \text { eff }}$ is included; details are given in Sect. 2.2. System characteristics 
are described by $C_{L}$. The backscatter coefficient $\beta$ can be separated into contributions from particles and air molecules

$\beta=\beta_{p}+\beta_{m}$.

The analytical solution of the lidar equation with respect to either $\beta_{p}$ or $\alpha_{p}$ is well established in the absence of trace gas absorption and commonly referred to as the "Klett solution" (e.g. Fernald et al., 1972; Klett, 1981). Under typical atmospheric conditions the $\beta_{p}$-retrieval is preferable, in particular in cases of low aerosol concentration and/or long wavelengths, as under these conditions the retrieval is less sensitive to errors of the assumed lidar ratio.

The lidar equation with water vapor absorption (Eq. 1) can be solved in different ways for $\beta_{p}$. All solutions can be expressed in this general form

$\beta_{p}(z)=\frac{Z_{i}(z)}{N_{i}(z)}-\beta_{m}(z)$ with $i=1,2,3,4$.

The first two approaches follow the solution described by Klett but with the additional water vapor absorption resulting in a more general form. If the range integration is performed in forward direction from the overlap range $z_{\text {ovl }}$ one gets

$$
\begin{aligned}
Z_{1}(z) & =z^{2} P(z) T_{\mathrm{w}, \mathrm{eff}}^{-2}\left(z_{\mathrm{ovl}}\right) \\
& \times \exp \left\{-2 \int_{z_{\mathrm{ovl}}}^{z}\left[\left(S_{p}-S_{m}\right) \beta_{m}-\alpha_{\mathrm{w}, \mathrm{eff}}\right] \mathrm{d} z^{\prime}\right\}
\end{aligned}
$$

with $S_{p}$ and $S_{m}$ being the particle and molecular lidar ratio respectively, and

$N_{1}(z)=C_{L}(1-\varepsilon)-2 \int_{z_{\text {ovl }}}^{z} S_{p}\left(z^{\prime}\right) Z_{1}\left(z^{\prime}\right) \mathrm{d} z^{\prime}$.

Here, in contrast to the original Klett-solution, additionally the effective water vapor extinction coefficient $\alpha_{\mathrm{w} \text {,eff }}$ appears. Note that using $z_{\mathrm{ovl}}$ as the lower boundary of the integrals in Eqs. (4) and (5) is an approximation applicable for cases of low overlap heights $z_{\text {ovl }}$ and/or long wavelengths as pointed out by Wiegner and Geiß (2012). This approximation is legitime for the term $Z_{1}(z)$, i.e., at wavelengths not affected by water vapor absorption, otherwise the factor $T_{\mathrm{w}, \mathrm{eff}}^{-2}\left(z_{\mathrm{ovl}}\right)$ has to be considered. As we want to investigate the effect of water vapor absorption on $\beta_{p}$-retrievals as precisely as possible (Sect. 5) we have also included the term $(1-\varepsilon)$ for $N_{1}(z)$ which is calculated as

$$
\varepsilon=2 \int_{0}^{z_{\mathrm{ovl}}} S_{p}\left(z^{\prime}\right) \beta\left(z^{\prime}\right) T_{\mathrm{m}}^{2}\left(z^{\prime}\right) T_{\mathrm{p}}^{2}\left(z^{\prime}\right) \mathrm{d} z^{\prime} \approx 2 z_{\mathrm{ovl}} S_{p} \beta\left(z_{\mathrm{ovl}}\right)
$$

and must be determined iteratively because $\beta\left(z_{\text {ovl }}\right)$ is initially unknown. Using typical values one gets $\varepsilon \approx 0.02$ in accordance with Wiegner and Geiß (2012) where it was stated that $\varepsilon$ is small compared to 1 , but was set to 0 for the sake of simplicity.

If the range integration is done towards the lidar, slightly different equations are found: for $Z_{2}(z)$ we get

$Z_{2}(z)=z^{2} P(z) \exp \left\{2 \int_{z}^{z_{\text {ref }}}\left[\left(S_{p}-S_{m}\right) \beta_{m}-\alpha_{\mathrm{w}, \mathrm{eff}}\right] \mathrm{d} z^{\prime}\right\}$

and for $N_{2}(z)$

$N_{2}(z)=\frac{z_{\text {ref }}^{2} P\left(z_{\text {ref }}\right)}{\beta_{m}\left(z_{\text {ref }}\right)+\beta_{p}\left(z_{\text {ref }}\right)}+2 \int_{z}^{z_{\text {ref }}} S_{p}\left(z^{\prime}\right) Z_{2}\left(z^{\prime}\right) \mathrm{d} z^{\prime}$

with a "meteorological" reference value $\beta_{p}\left(z_{\text {ref }}\right)$.

Two additional approaches are based on a simple rearrangement of the lidar Eq. (1):

$P(z) T_{\mathrm{w}, \mathrm{eff}}^{-2}(z)=P^{\prime}(z)=C_{L} \frac{\beta(z)}{z^{2}} T_{\mathrm{p}}^{2}(z) T_{\mathrm{m}}^{2}(z)$.

Then, the "standard" Klett solution, i.e., without an absorption term, can be applied to $P^{\prime}$ (instead of $P$ ). As a consequence $Z_{3}(z)$ and $N_{3}(z)$ can be introduced as

$Z_{3}(z)=z^{2} P^{\prime}(z) \exp \left\{-2 \int_{z_{\mathrm{ovl}}}^{z}\left(S_{p}-S_{m}\right) \beta_{m} \mathrm{~d} z^{\prime}\right\}$

and

$N_{3}(z)=C_{L}(1-\varepsilon)-2 \int_{z_{\mathrm{ovl}}}^{z} S_{p}\left(z^{\prime}\right) Z_{3}\left(z^{\prime}\right) \mathrm{d} z^{\prime}$.

They can be used instead of $Z_{1}(z)$ and $N_{1}(z)$ if the ceilometer has been absolutely calibrated. The solution corresponding to the backward integration $\left(Z_{2}(z), N_{2}(z)\right)$ is

$Z_{4}(z)=z^{2} P^{\prime}(z) \exp \left\{2 \int_{z}^{z_{\text {ref }}}\left(S_{p}-S_{m}\right) \beta_{m} \mathrm{~d} z^{\prime}\right\}$

and

$N_{4}(z)=\frac{z_{\mathrm{ref}}^{2} P^{\prime}\left(z_{\mathrm{ref}}\right)}{\beta_{m}\left(z_{\mathrm{ref}}\right)+\beta_{p}\left(z_{\mathrm{ref}}\right)}+2 \int_{z}^{z_{\mathrm{ref}}} S_{p}\left(z^{\prime}\right) Z_{4}\left(z^{\prime}\right) \mathrm{d} z^{\prime}$.

For the second group again the knowledge of the profile of $\alpha_{\mathrm{w}, \mathrm{eff}}(z)$ is required but expressed in the form of the transmission $T_{\mathrm{w}, \text { eff }}(z)$, and applied to the raw signal before the actual inversion is done. This procedure was used by Markowicz et al. (2008).

Which of the four formulations is applied, mainly depends on the ceilometer signal and the meteorological conditions, e.g., a backward solution typically can only be applied to 
Table 1. Wavelength-dependence of optical properties: extinction coefficients are given in $\mathrm{km}^{-1}$, backscatter coefficients in $\mathrm{km}^{-1} \mathrm{sr}^{-1}$. For the calculation of $\alpha_{m}$ (Bodhaine et al., 1999) we use $p=1000 \mathrm{hPa}$ and $T=290 \mathrm{~K}$ as an example. For $T_{m}^{2}$ we assume a layer of $1 \mathrm{~km}$ thickness (typical for standard atmospheres). $\beta_{p}$ is calculated from the prescribed $\alpha_{p}$ with a lidar ratio of $S_{p}=50 \mathrm{sr}$.

\begin{tabular}{lllll}
\hline & $908 \mathrm{~nm}$ & $910 \mathrm{~nm}$ & $912 \mathrm{~nm}$ & $1064 \mathrm{~nm}$ \\
\hline$\alpha_{p}$ & $5.0165 \times 10^{-2}$ & $5.0000 \times 10^{-2}$ & $4.9836 \times 10^{-2}$ & $3.9548 \times 10^{-2}$ \\
$T_{p}^{2}$ & 0.90454 & 0.90484 & 0.90509 & 0.92395 \\
$\alpha_{m}$ & $1.4801 \times 10^{-3}$ & $1.4670 \times 10^{-3}$ & $1.4541 \mathrm{e} \times 10^{-3}$ & $0.7824 \times 10^{-3}$ \\
$T_{m}^{2}$ & 0.99704 & 0.99707 & 0.99710 & 0.99844 \\
$\beta_{p}$ & $1.0033 \times 10^{-3}$ & $1.0000 \times 10^{-3}$ & $0.9967 \times 10^{-3}$ & $0.7910 \times 10^{-3}$ \\
$\beta_{m}$ & $1.7667 \times 10^{-4}$ & $1.7511 \times 10^{-4}$ & $1.7357 \times 10^{-4}$ & $0.9340 \times 10^{-4}$ \\
$\beta$ & $1.1800 \times 10^{-3}$ & $1.1751 \times 10^{-3}$ & $1.1703 \times 10^{-3}$ & $0.8844 \times 10^{-3}$ \\
\hline
\end{tabular}

nighttime measurements and long temporal averages. The remaining choice between option 1 vs. option 3 or option 2 vs. option 4 is more or less a matter of personal preference.

The solution for $\beta_{p}$ finally can be found if the signals are calibrated. Thus either the boundary value at $z_{\text {ref }}$ (Rayleigh calibration), see Eqs. (8) and (13), respectively, or $C_{L}$ must be determined (absolute calibration), see Eqs. (5) and (11). Basically, the Rayleigh calibration can be understood as finding a range $z_{\text {ref }}$ where the slopes of the measured and a hypothetical signal of an aerosol-free atmosphere agree: in case of Eq. (8) the measured signal must be compared with a hypothetical signal of an aerosol-free, but possibly water vapor containing atmosphere, in case of Eq. (13) the water vapor corrected signal $P^{\prime}(z)$ is compared with a hypothetical signal of an aerosol-free atmosphere. Under realistic meteorological conditions it is very likely that in altitude ranges where no aerosols are present the water vapor concentration is also virtually zero. Consequently, finding a reference height $z_{\text {ref }}$ from the signal slope should be straight forward, provided that the signal-to-noise ratio is sufficiently large in that altitude. However, in any case the water vapor absorption $\left(\alpha_{\mathrm{w}, \text { eff }}\right.$ or $\left.T_{\mathrm{w}, \text { eff }}\right)$ must be estimated.

If the absolute calibration is applied, the lidar equation is solved for $C_{L}$, and $C_{L}$ can be determined if all other parameters are known (Wiegner and Geiß, 2012). This requirement is difficult to fulfill: as $\beta_{p}$ at $\lambda=910 \mathrm{~nm}$ cannot be determined independently by, e.g., a reference lidar system, it must be extrapolated from $\beta_{p}$ at $1064 \mathrm{~nm}$ or interpolated between 532 and $1064 \mathrm{~nm}$. The extinction coefficient $\alpha_{p}$ is estimated by means of an assumed lidar ratio. As a conclusion, not only the uncertainty of the estimated water vapor extinction influences the accuracy of $C_{L}$ but also the uncertainties of $\beta_{p}$ of the reference lidar, the wavelength dependence of $\beta_{p}$, and the lidar ratio. Thus, the measurements for the absolute calibration must be selected very carefully, in particular the presence of multi-layered aerosol distributions (possibly with different aerosol types) should be avoided to facilitate the wavelength extrapolation. In summary, absolute calibration of ceilometer measurements at $\lambda \approx 910 \mathrm{~nm}$ is inherently more prone to errors than at $1064 \mathrm{~nm}$.

\subsection{Spectral dependence of optical properties}

As already mentioned the lidar equation is expressed as a monochromatic formulation. If this approach should be used for ceilometers with an emitted spectrum of a few nanometers width within a water vapor absorption band, the wavelength dependence of the optical properties must be investigated. In particular, $\alpha_{\mathrm{w}, \text { eff }}$ must be calculated.

For such small wavelength intervals the spectral dependence of $\alpha_{m}$ and $\alpha_{p}$ can be neglected as can easily be demonstrated (see Table 1): if we consider, e.g., a spectral range of $\pm 2 \mathrm{~nm}$ at a wavelength of $\lambda=910 \mathrm{~nm}$, and assume $\alpha_{p}=0.05 \mathrm{~km}^{-1}$ and an Angström exponent $\kappa=1.5$ as representative values for our measurement site at Munich, Germany, the particle extinction coefficient $\alpha_{p}$ (and $\tau_{p}$ correspondingly) varies by approximately $\pm 0.3 \%$. The variation of the squared transmission $T_{\mathrm{p}}^{2}$ is one order of magnitude smaller. Even for larger optical depth the variation of $T_{\mathrm{p}}^{2}$ is negligible. Note that in Table 1 the thickness of the layer is assumed to be $1 \mathrm{~km}$ (according to the standard atmospheres, Anderson et al., 1986). The corresponding variation of the Rayleigh extinction coefficient $\alpha_{m}$ (e.g. Bodhaine et al., 1999 ) is of the order of $\pm 1 \%$, however, as $\alpha_{m}$ is more than one order of magnitude smaller than $\alpha_{p}$ the squared transmission $T_{\mathrm{m}}^{2}$ can also be considered as wavelength-independent (see Table 1).

The spectral variation of $\beta_{p}$ is similar to that of $\alpha_{p}$ as the lidar ratio $S_{p}$ can be expected to be almost constant in the spectral interval. The variation of $\beta_{m}$ is equal to the variation of $\alpha_{m}$ and thus somewhat larger, but as $\beta_{m} \ll \beta_{p}$ the total backscatter coefficient $\beta$ is also virtually wavelengthindependent (approximately $\pm 0.4 \%$, see Table 1 ).

As a consequence only the wavelength-dependence of the water vapor absorption must be considered. If we understand the ceilometer measurement as a series of pulses at $N$ different wavelengths $\lambda_{i}$ (from an interval of a few nanometers width) and a weight $a_{i}$ as a measure of the frequency of occurrence of wavelength $\lambda_{i}$ or as a factor describing a wavelength dependence of the lidar constant we can express the lidar equation as follows: 
$P(z)=\frac{\sum_{i=1}^{N} a_{i} C_{L} \frac{\beta(z)}{z^{2}} T_{\mathrm{p}}^{2}(z) T_{\mathrm{m}}^{2}(z) T_{\mathrm{w}}^{2}\left(z, \lambda_{i}\right)}{\sum_{i=1}^{N} a_{i}}$.

Here, $P(z)$ is "normalized to one shot" in accordance with Eq. (1). Then, the effective water vapor transmission $T_{\mathrm{w}, \mathrm{eff}}(z)$ can be defined as

$$
T_{\mathrm{w}, \mathrm{eff}}^{2}(z)=\frac{\sum_{i=1}^{N} a_{i} T_{\mathrm{w}}^{2}\left(z, \lambda_{i}\right)}{\sum_{i=1}^{N} a_{i}}
$$

and the "spectral" lidar Eq. (14) can be handled in the well known "monochromatic" way as already applied in Eqs. (1) and (9). The only remaining task is the determination of $T_{\mathrm{w}, \mathrm{eff}}^{2}$ or an equivalent quantity, e.g., the effective water vapor absorption coefficient $\alpha_{\mathrm{w}, \mathrm{eff}}$, as a function of height. If the relation between $\alpha_{\mathrm{w}, \text { eff }}$ and $T_{\mathrm{w}, \text { eff }}$ is defined as usual, see Eq. (2), we obtain for a layer from $z_{1}$ to $z_{2}$ :

$\alpha_{\mathrm{w}, \mathrm{eff}}=\frac{1}{2\left(z_{2}-z_{1}\right)} \ln \left(\frac{T_{\mathrm{w}, \mathrm{eff}}^{2}\left(z_{1}\right)}{T_{\mathrm{w}, \mathrm{eff}}^{2}\left(z_{2}\right)}\right)$

Now, $\alpha_{\mathrm{w}, \text { eff }}$ can be used in Eqs. (4) and (7). The knowledge of $\alpha_{\mathrm{w}, \text { eff }}$ or $T_{\mathrm{w}, \text { eff }}$ is also a prerequisite for the calibration of the signals as discussed in Sect. 2.1.

\section{Effective water vapor absorption}

For the determination of the effective absorption coefficients of water vapor $\alpha_{\mathrm{w}, \text { eff }}$ we use the atmospheric radiative transfer simulator (ARTS, Buehler et al., 2005). Though for ceilometer applications the spectral range between 900 and $925 \mathrm{~nm}$ probably would be sufficient, we consider a slightly larger interval from 895 to $930 \mathrm{~nm}$ (wavenumbers $\widetilde{v}$ between 11173 and $10753 \mathrm{~cm}^{-1}$ ). The spectral resolution $\Delta \widetilde{v}$ is set to $0.01 \mathrm{~cm}^{-1}$, resulting in 42050 different calculations. Spectroscopic data are based on the HITRAN (Rothman et al., 2005) data base and the MT-CKD continuum model (Clough et al., 2005), the same data set as used by Gasteiger et al. (2014). Spectral absorption cross sections depend on temperature, pressure and the water vapor concentration, consequently, these profiles are required as input. Note that the output of the ARTS-simulations are spectral optical depths of water vapor. Profiles of the water vapor number concentration $n_{\mathrm{w}}\left(\mathrm{in} \mathrm{m}^{-3}\right)$ are determined according to

$n_{\mathrm{W}}=7.25 \times 10^{22} \varrho_{\mathrm{w}} R_{\mathrm{W}}$

with $R_{\mathrm{W}}=0.462 \mathrm{~J} \mathrm{~g}^{-1} \mathrm{~K}^{-1}$ as the gas constant of water vapor, the absolute humidity $\varrho_{\mathrm{w}}$ (in $\mathrm{g} \mathrm{m}^{-3}$ ) $\varrho_{\mathrm{w}}=\frac{f_{\text {rel }} p_{\mathrm{s}}}{R_{\mathrm{w}} T}$

the relative humidity $f_{\text {rel }}$, and the water vapor saturation pressure $p_{\mathrm{s}}$ that can be derived from Magnus' formula. The constant in Eq. (17) results from the standard values for temperature, pressure and number concentration of air molecules, and is given in $\mathrm{K}(\mathrm{Nm})^{-1}$.

The maximum height of the model atmosphere was set to $10 \mathrm{~km}$ which is certainly sufficient in view of the measurement range of ceilometers.

To investigate the influence of different water vapor distributions we use six standard atmospheric models (USstandard, mid-latitude summer and winter, subarctic summer and winter, tropical; Anderson et al., 1986) for our simulations. The water vapor content expressed as precipitable water $w$ of these atmospheres is between $w=4.2 \mathrm{~kg} \mathrm{~m}^{-2}$ (subarctic winter) and $w=41.7 \mathrm{~kg} \mathrm{~m}^{-2}$ (tropical). The vertical resolution of all profiles is $1 \mathrm{~km}$ below $25 \mathrm{~km}$. As the actual central wavelength and the width of the emission spectrum of a ceilometer could be temperature dependent and not always known in detail we also investigate different spectra. For the CL51 ceilometer, e.g., $\lambda_{0}=910 \pm 10 \mathrm{~nm}$ at $25^{\circ} \mathrm{C}$ with a drift of $0.27 \mathrm{~nm} \mathrm{~K}^{-1}$ is specified by Vaisala. We assume a Gaussian shape of the spectrum with $\lambda_{0}$ between $901 \mathrm{nd} 919 \mathrm{~nm}$, and a full width at half maximum (FWHM, henceforward referred to as $\Delta \lambda$ ) between 1.0 and $4.0 \mathrm{~nm}$. According to Vaisala, $\Delta \lambda$ is of the order of $3.4 \mathrm{~nm}$. From these parameters the weights $a_{i}$ required for Eq. (15) are calculated. Note that the relation between the standard deviation of the Gauss function $\sigma$ and $\Delta \lambda$ is

$\mathrm{FWHM}=\Delta \lambda=2 \sigma \sqrt{2 \ln 2} \approx 2.355 \sigma$.

Figure 1 gives an example of the spectral transmission for the mid-latitude summer atmosphere and two assumed emission spectra of the laser. Shown is $T_{\mathrm{w}}^{2}(\lambda)$ from the surface to 1 and $10 \mathrm{~km}$, respectively, and the Gaussian curves for $\lambda_{0}=910 \mathrm{~nm}$, and $\Delta \lambda=2.0 \mathrm{~nm}$ and $\Delta \lambda=4.0 \mathrm{~nm}$ as a "narrow" and a "broad" case. It is obvious that in all cases the width of the emission spectrum is much larger than the spectroscopic structure of the absorption so that in any case a large number of strong and weak lines are averaged. Nevertheless it is expected that the effective transmission depends on $\lambda_{0}$ and $\Delta \lambda$ as Fig. 2 may illustrate.

It shows $\alpha_{\mathrm{w}, \text { eff }}$ in the lowermost layer of the model atmosphere as a function of $\lambda_{0}$ and its sensitivity on $\Delta \lambda$. The six above-mentioned standard atmospheres can be distinguished by color whereas the different $\Delta \lambda$ can be identified by the symbols. It is obvious that the different water vapor contents of the standard atmospheres have the most significant influence on $\alpha_{\mathrm{w}, \text { eff }}$ with largest values for the tropical case. This points out that it is crucial to have water vapor profiles available from radiosondes (for their accuracy see, e.g. Miloshevich et al., 2009; Dirksen et al., 2014) or analyses of NWP models (e.g., NFS by NCEP or IFS by ECMWF) 


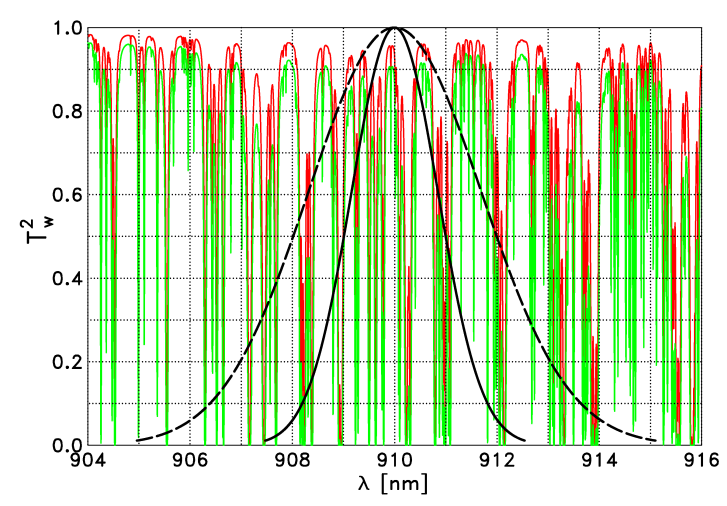

Figure 1. Squared water vapor transmission $T_{\mathrm{w}}^{2}$ between the surface and $1 \mathrm{~km}$ (red) and $10 \mathrm{~km}$ (green) in the spectral range between 904 and $916 \mathrm{~nm}$, mid-latitude summer conditions. For demonstration two Gaussian emission curves with $\Delta \lambda=2 \mathrm{~nm}$ (black, solid line) and $\Delta \lambda=4 \mathrm{~nm}$ (black, dashed) are shown, $\lambda_{0}=910 \mathrm{~nm}$.

for the correction of ceilometer measurements. It can also be seen that for a given atmosphere $\alpha_{\mathrm{w}, \text { eff }}$ changes with $\lambda_{0}$ quite differently: e.g., absorption increases by almost a factor of 2 from $\lambda_{0}=905$ to $908 \mathrm{~nm}$, whereas it varies only by less than $10 \%$ between $\lambda_{0}=908$ to $918 \mathrm{~nm}$ as indicated by the dashed lines. Thus, the error of the absorption coefficient $\alpha_{\mathrm{w}, \text { eff }}$ due to a temperature induced change of $\lambda_{0}$ by 1 or $2 \mathrm{~nm}$ can be quite different. The variability with $\Delta \lambda$ depends on $\lambda_{0}$ but is in most cases comparably small.

For the analysis of actual ceilometer data a better vertical resolution than that of the standard atmospheres is desired resulting in a significant increase of computing time and mass storage. For compensation a reduction of the spectral resolution of ARTS could be an option. As a consequence, we have repeated all calculations with different spectral resolutions using $\Delta \widetilde{v}=0.01 \mathrm{~cm}^{-1}$ as reference. It was found that for a reduced spectral resolution of $\Delta \widetilde{v}=0.1 \mathrm{~cm}^{-1}$ the relative deviation of $\alpha_{\mathrm{w}, \text { eff }}$ from the reference is less than $2 \times 10^{-3}$ for $\Delta \lambda \leq 2 \mathrm{~nm}$ and less than $5 \times 10^{-4}$ for $\Delta \lambda \geq 2.5 \mathrm{~nm}$. In case of $\Delta \widetilde{\nu}=0.2 \mathrm{~cm}^{-1}$ the relative deviation is still small, but not negligible: in most cases it is between $1 \times 10^{-2}$ and $1 \times 10^{-3}$. Thus, it is justified to reduce the spectral resolution of ARTS to $\Delta \widetilde{v}=0.1 \mathrm{~cm}^{-1}$.

We conclude that for correcting ceilometer data influenced by water vapor absorption the following information - ordered by decreasing relevance - is essential: the water vapor concentration profile, the central wavelength of the diode laser and the width of its spectrum.

\section{Correction function for water vapor absorption}

As already stated in Sect. 2, profiles of $T_{\mathrm{w}, \mathrm{eff}}^{2}(z)$ are required to correct ceilometer measurements for water vapor absorp-

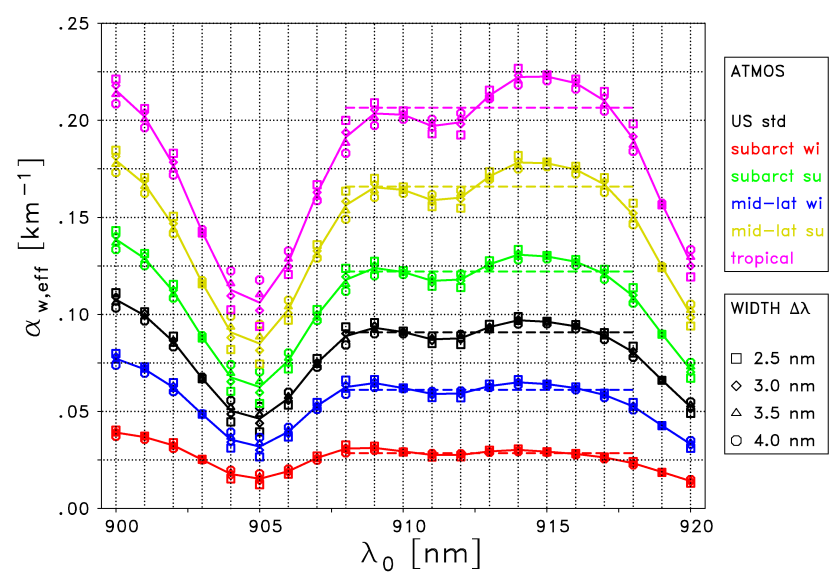

Figure 2. Effective water vapor absorption coefficient $\alpha_{\mathrm{w}, \text { eff }}$ in the lowermost layer $(0-1 \mathrm{~km})$ for six standard atmospheres and different $\Delta \lambda$ as indicated in the legend. The dashed lines give the averages over the spectral range from 908 to $918 \mathrm{~nm}$.

tion. Calculations with high spectral resolution taking into account the actual water vapor, temperature and pressure distribution, are however too expensive for large data sets or near-real time applications. For this purpose we aim at an approximative solution. As reference we define ARTS simulations with a spectral resolution of $\Delta \widetilde{\mathcal{v}}=0.1 \mathrm{~cm}^{-1}$, i.e., 4206 simulations for the spectral range between 895 and $930 \mathrm{~nm}$.

\subsection{Mid-latitude case}

As input for our water vapor absorption calculations we choose data from all radiosonde ascents of the year 2012 at Oberschleißheim ( $8 \mathrm{~km}$ northwest of the ceilometer site in Munich, WMO station identifier 10868), that reached at least $10 \mathrm{~km}$ above the ground. This results in a total number of 647 profiles of $T, p$ and relative humidity $f_{\text {rel }}$. These soundings are regarded as representative for continental mid-latitude sites, the annual mean and the standard deviation of the atmospheric water vapor content is $w=15.9 \pm 7.7 \mathrm{~kg} \mathrm{~m}^{-2}$. With the spectral optical depths of water vapor $\tau_{\mathrm{w}}$ provided by the ARTS-calculations the corresponding absorption cross section $\sigma_{\mathrm{w}}\left(t_{i}, \lambda_{j}, z_{k}\right)$ at each wavelength grid point $j,(j \leq 4206)$, and each radiosonde ascent (consecutively numbered according to time $t_{i}$, here $i \leq 647$ ) at level $k$ ( $k \leq 1000$, for $10 \mathrm{~m}$ vertical resolution) can be derived from Eq. (20)

$\sigma_{\mathrm{w}}\left(t_{i}, \lambda_{j}, z_{k}\right)=\frac{\tau_{\mathrm{w}}\left(t_{i}, \lambda_{j}, z_{k}\right)}{\Delta z n_{\mathrm{w}}\left(t_{i}, z_{k}\right)}$.

In the spectral range between 895 and $930 \mathrm{~nm}$ the absorption cross section covers a wide range between $\sigma_{\mathrm{w}}=10^{-26} \mathrm{~cm}^{2}$ and $\sigma_{\mathrm{w}}=10^{-21} \mathrm{~cm}^{2}$, and the height-dependence is quite variable. It can increase or decrease with height depending on the distance of the specific wavelength from a line center. 
Two extreme cases are shown in Fig. 3: at $\lambda=908.957 \mathrm{~nm}$ (left panel) the variability of $\sigma_{\mathrm{w}}$ over the 647 atmospheric situations is very small, i.e., the 10th percentile and the 90th percentile deviate in the order of $\pm 0.5 \%$ from the average $\overline{\sigma_{\mathrm{w}}}\left(\lambda_{j}, z_{k}\right)$ at each level. At $\lambda=905.885 \mathrm{~nm}$ (right panel) one of the rare cases occurs where the deviation is in the order of $\pm 10 \%$. If we consider all levels $k$ and all wavelengths $j$ (i.e., a total of 4.2 million cases), the deviation of $\sigma_{\mathrm{w}}$ from the corresponding average is below $5 \%$ in $81 \%$ of all cases, and below $10 \%$ in $97 \%$ of all cases. If the spectral range is restricted to wavelengths smaller than $925 \mathrm{~nm}$, the corresponding values are even larger with 87 and $99 \%$, respectively. The "spikes" are numerical effects caused by the very high vertical resolution of the ARTS calculations and occur in cases of very strong gradients of the relative humidity measured by the radiosondes. However, these cases are quite rare as can be deduced from the smooth curves of the percentiles.

Thus, it can be expected that it is sufficient for the water vapor correction to consider at each wavelength one profile of $\overline{\sigma_{\mathrm{w}}}$ averaged over "all" atmospheric states. As a consequence we store the averaged absorption cross section $\overline{\sigma_{\mathrm{w}}}\left(\lambda_{j}\right.$, $z_{k}$ ) with a spectral resolution of $\Delta \widetilde{v}=0.1 \mathrm{~cm}^{-1}$ and a vertical resolution of $10 \mathrm{~m}$ in an archive (netcdf format).

On the basis of these findings a water vapor correction scheme for routine evaluation of ceilometer data, named "WAPL", has been developed: from radiosonde profiles or numerical models the water vapor number density $n_{\mathrm{w}}$ is calculated according to Eqs. (17) and (18). The emission spectrum $\left(\lambda_{0}, \Delta \lambda\right)$ of the laser must be estimated for the individual ceilometer based on information of the manufacturer and might be time-dependent. With the tabulated mean absorption cross-section $\overline{\sigma_{\mathrm{w}}}(\lambda, z)$ of the above-mentioned archive an (approximative) water vapor transmission $T_{\mathrm{w}, \mathrm{prx}}(\lambda, z)$ can be calculated as follows:

$T_{\mathrm{w}, \mathrm{prx}}(\lambda, z)=\exp \left\{-\int_{0}^{z} n_{\mathrm{w}}\left(z^{\prime}\right) \overline{\sigma_{\mathrm{w}}}\left(\lambda, z^{\prime}\right) \mathrm{d} z^{\prime}\right\}$.

Finally, the effective (approximative) water vapor transmission $T_{\mathrm{w}, \text { eff,prx }}(z)$ is derived analogously to Eq. (15) and used to determine $\beta_{p}$ (Eq. 3). Figure 4 may further clarify the entire procedure of WAPL; the required input for the evaluation is highlighted by the yellow boxes.

To characterize the accuracy of the effective transmission we define a function $G$ as

$G\left(t_{i}, z\right)=\frac{T_{\mathrm{w}, \mathrm{eff}, \mathrm{prx}}^{2}\left(t_{i}, z\right)}{T_{\mathrm{w}, \mathrm{eff}, \text { ref }}^{2}\left(t_{i}, z\right)}-1$.

To get independent results the accuracy of WAPL is tested using all radiosonde ascents of the year 2013 (636 cases) of Oberschleißheim. The water vapor content of $w=14.7 \pm 7.1 \mathrm{~kg} \mathrm{~m}^{-2}$ is similar to the previous year. From these data the actual water vapor number concentration can

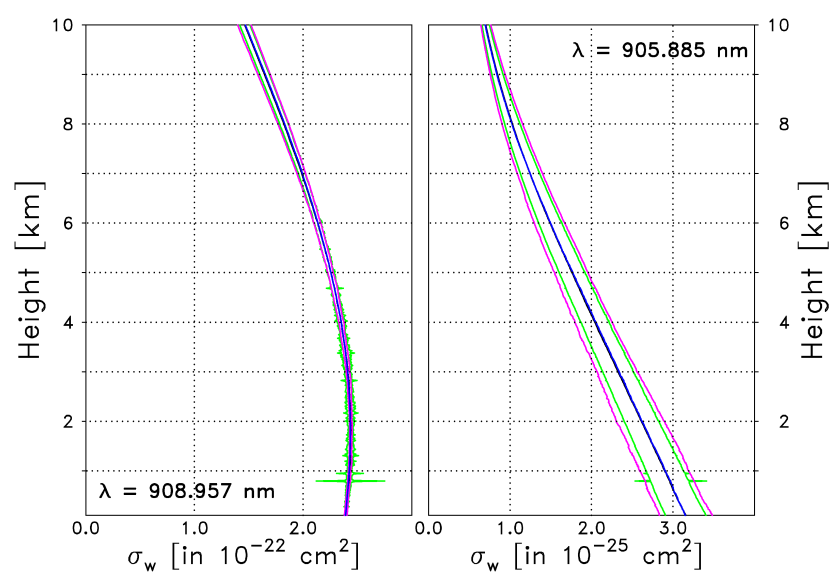

Figure 3. Vertical profile of the water vapor absorption cross section $\overline{\sigma_{\mathrm{W}}}(\lambda, z)$ : average over 647 atmospheric profiles (black), one standard deviation from the average (green), median (blue) and $10 \%$ and $90 \%$ percentile (pink). The wavelength is $\lambda=908.957 \mathrm{~nm}$ (left panel) and $\lambda=905.885 \mathrm{~nm}$ (right panel), respectively. $\overline{\sigma_{\mathrm{W}}}$ is given in $10^{-22} \mathrm{~cm}^{2}$ (left panel) and $10^{-25} \mathrm{~cm}^{2}$ (right panel).

readily be calculated. By assuming a Gaussian-shaped emission spectrum of the laser diode with a realistic value of $\Delta \lambda=3.5 \mathrm{~nm}$, considering the spectral range of \pm 3 standard deviations (i.e., $2.548 \Delta \lambda$, see Eq. 19), and using our reference spectral resolution of $\Delta \widetilde{v}=0.1 \mathrm{~cm}^{-1}$, this requires 1080 out of 4206 "individual" wavelengths ( $N$ in Eq. 15) to calculate $T_{\mathrm{w}, \mathrm{eff}, \mathrm{prx}}^{2}$. Finally we get 636 profiles of $G\left(t_{i}, z\right)$.

An example of the performance of WAPL, expressed in terms of $G$, is given in Fig. 5 for $\lambda_{0}=905 \mathrm{~nm}$ and $\Delta \lambda=3.5 \mathrm{~nm}$. It can be seen that the averaged $\overline{G(z)}$ and the median $G_{50}(z)$ are virtually zero (left panel), the percentiles $\left(G_{10}(z)\right.$ and $\left.G_{90}(z)\right)$ are within $\pm 0.3 \%$, and that even the minimum and maximum values caused by the rare spikes mentioned above stay within -0.5 and $0.3 \%$ for all radio soundings and all heights. Similar results can be found for other $\lambda_{0}$ : as can be anticipated from Fig. 2 the errors are slightly larger around $907 \mathrm{~nm}$ and smallest around $912 \mathrm{~nm}$, but the absolute values of $G_{10}(z)$ and $G_{90}(z)$ are never larger than $0.3 \%$. So we conclude that the annual variability of $p$ and $T$ has no significant influence on $\sigma_{\mathrm{w}}$ and consequently WAPL is suitable to correct the $\beta_{p}$-retrieval for water vapor.

This conclusion remains valid if we reduce the vertical resolution of the stored $\overline{\sigma_{\mathrm{w}}}$ to $100 \mathrm{~m}$, but not if we reduce the spectral resolution (we have considered $\Delta \widetilde{v} \leq 1 \mathrm{~cm}^{-1}$ ). Only if we select $\Delta \widetilde{v}=0.2 \mathrm{~cm}^{-1}$, the percentiles $G_{10}(z)$ and $G_{90}(z)$ are within -0.4 and $0.3 \%$. But as soon as $\Delta \widetilde{v} \geq 0.3 \mathrm{~cm}^{-1}$ (Fig. 5, center and right panels for $\Delta \widetilde{v}=0.3 \mathrm{~cm}^{-1}$ and $\Delta \widetilde{v}=0.5 \mathrm{~cm}^{-1}$, respectively) the deviations generally increase and $T_{\mathrm{w}, \text { eff,ref }}^{2}\left(t_{i}, z\right)$ is systematically over- or underestimated. As can be seen, e.g., in the rightmost panel of Fig. 5, the transmission is systematically overestimated; $G_{50}(z)$ is in the order of $0.5 \%$. Note that the accuracy of the approximation is not correlated with $\lambda_{0}$ and 


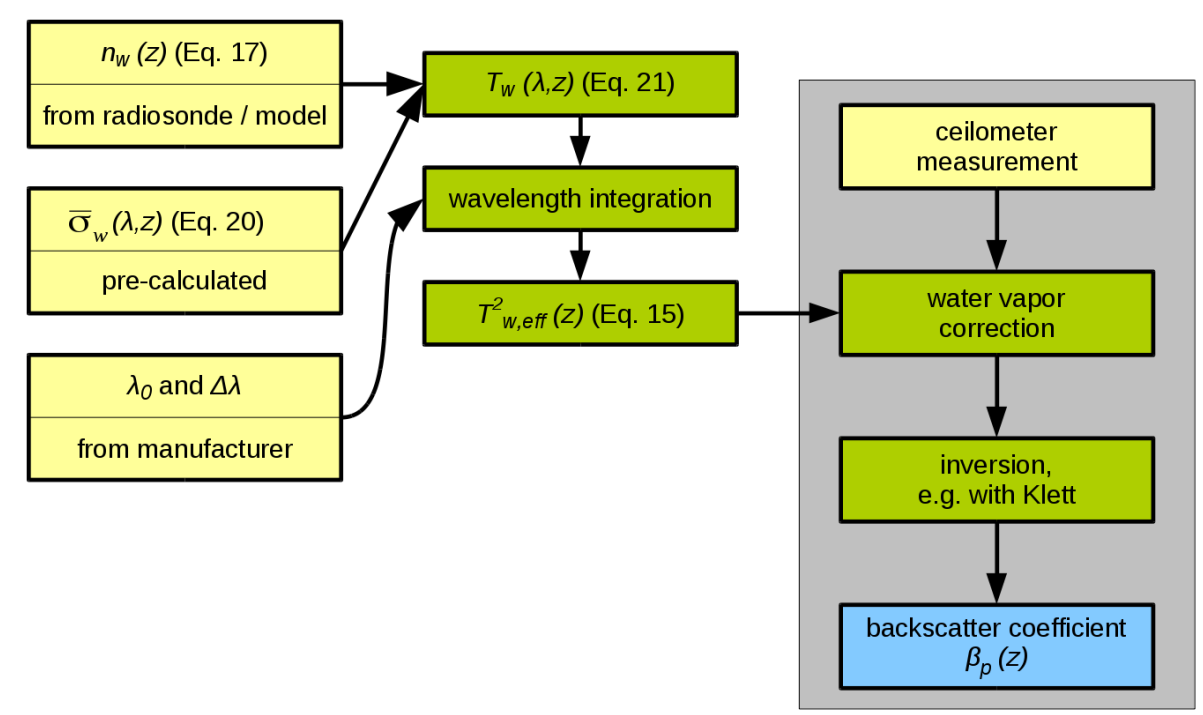

Figure 4. Flow chart of WAPL: correction for water vapor absorption in the determination of the aerosol backscatter coefficient $\beta_{p}$ (blue box). The yellow boxes indicate the input required for WAPL whereas steps concerning calculations are shown in green.
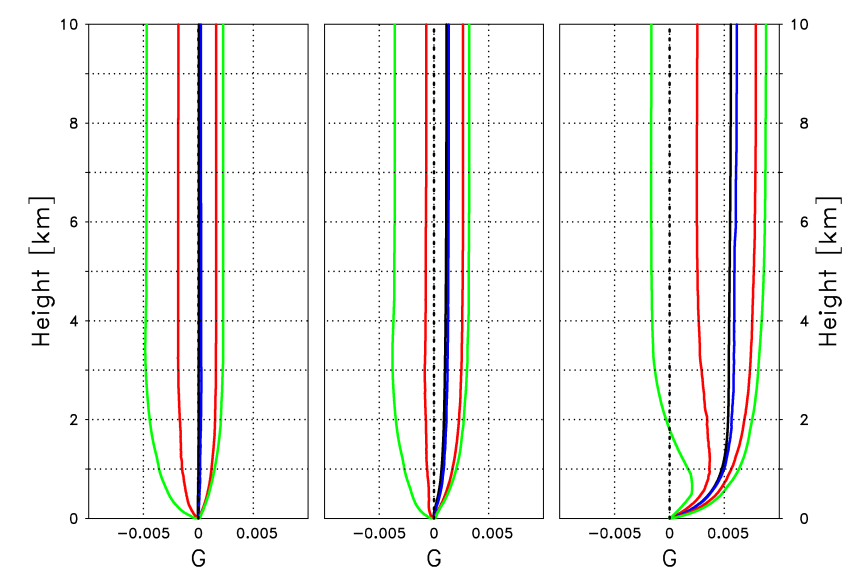

Figure 5. Deviation of the approximative squared transmissions $T_{\text {eff,prx }}^{2}\left(t_{i}, z\right)$ from the reference case expressed in terms of the function $G\left(t_{i}, z\right)$ : average over 636 cases (black), $G_{50}(z)$ (blue), $G_{10}(z)$ and $G_{90}(z)$ percentile (red), and the minimum and maximum values (green). The emission spectrum of the laser diode is defined by $\lambda=905 \mathrm{~nm}$ and $\Delta \lambda=3.5 \mathrm{~nm}$. The three panels (from left to right panels) are for different spectral resolutions of $\overline{\sigma_{\mathrm{W}}}=0.1,0.3$, and $0.5 \mathrm{~cm}^{-1}$.

the spectral resolution. At $\lambda_{0}=906 \mathrm{~nm}$ the median $G_{50}(z)$ is, e.g., virtually zero for $\Delta \widetilde{v}=0.8 \mathrm{~cm}^{-1}$, but up to $+1.3 \%$ for $\Delta \widetilde{v}=0.7 \mathrm{~cm}^{-1}$, and $-2.3 \%$ for $\Delta \widetilde{v}=0.9 \mathrm{~cm}^{-1}$. Due to their "unpredictable" magnitude these errors can hardly be implemented in an error analysis of the ceilometer retrieval. Thus, we recommend using a spectral resolution of $\Delta \widetilde{v} \leq 0.2 \mathrm{~cm}^{-1}$.

\subsection{Tropical case}

To investigate the validity of WAPL and to test whether one archived set of annual averages of water vapor absorption cross sections $\overline{\sigma_{\mathrm{w}}}$ is sufficient for global applications we have repeated the calculations for Acapulco, Mexico $\left(16.84^{\circ} \mathrm{N}, 99.93^{\circ} \mathrm{W}\right.$, station identifier 76805$)$. The water vapor distribution significantly differs from the situation at Oberschleißheim: the annual mean of the water vapor content $w=46.0 \pm 11.4 \mathrm{~kg} \mathrm{~m}^{-2}$ is almost three times larger and the absolute values of the variability are larger as well. We use radiosonde ascents of 2012 (453 cases) as reference and data from 2013/14 (512 cases) for the validation.

To illustrate the results in comparison to the mid-latitude station at Oberschleißheim, Fig. 6 shows the profile of water vapor absorption cross section $\overline{\sigma_{\mathrm{w}}}(\lambda, z)$ at the same two wavelengths as before (see Fig. 3). It is obvious that the height-dependence is similar, however, the absolute values of $\overline{\sigma_{\mathrm{w}}}(\lambda, z)$ are slightly larger at Acapulco for most height levels. The variability of the sample of 1 year's ascents is somewhat smaller: at both wavelengths, especially at $\lambda=905.885 \mathrm{~nm}$, the percentiles are closer to the average for the Acapulco site. The "spikes" of the absorption cross section profiles are more frequent than for the mid-latitude case, likely a result of larger errors of the humidity measurements of the radiosondes. However, these cases do not prevent the determination of smooth $\overline{\sigma_{\mathrm{w}}}$-profiles.

The accuracy of WAPL is again expressed in terms of $G\left(t_{i}\right.$, $z$ ), see Eq. (22). The results are very similar to the previous mid-latitude case and the same conclusions hold. If a spectral resolution of $\Delta \widetilde{v}=0.1 \mathrm{~cm}^{-1}$ is used, $G_{50}(z)$ is virtually zero for all $\lambda_{0}$ and all levels, and the percentiles are within 


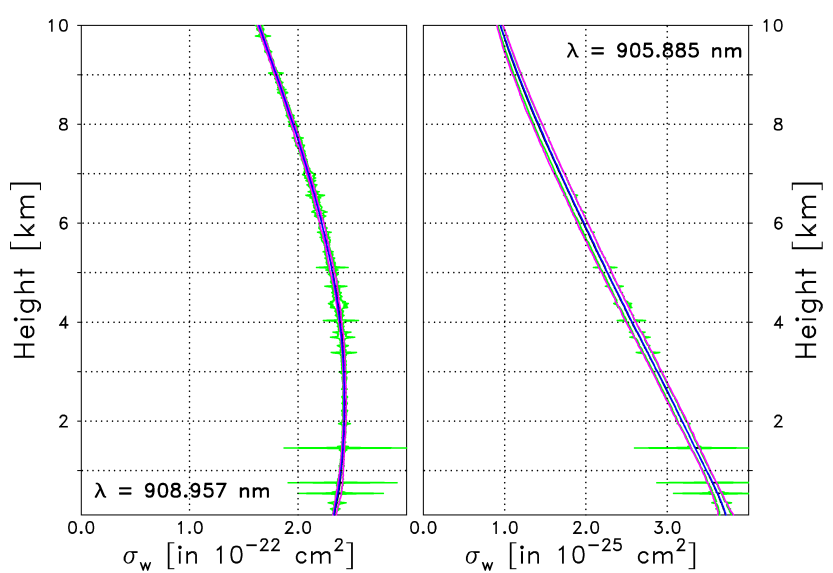

Figure 6. Same as Fig. 3 but $\overline{\sigma_{\mathrm{W}}}(\lambda, z)$ as derived from radiosonde data of Acapulco, Mexico.

$\pm 0.2 \%$. Largest deviations occur for poor spectral resolution and are up to $\pm 4.0 \%$.

\subsection{Sensitivity to climate zone}

It has been shown that annual mean absorption cross sections of water vapor can be used for routine applications. We want to briefly discuss whether it is necessary to provide $\overline{\sigma_{\mathrm{w}}}(\lambda, z)$ tables for the site of the ceilometer, or if tables derived for other sites are acceptable. For this purpose we apply WAPL as introduced above, but use the mean absorption cross sections found for the mid-latitudes for the tropical site and vice versa. In contrast to the previous examples, $\lambda_{0}=912 \mathrm{~nm}$ is selected for Fig. 7, as for this wavelength the effect is largest.

It can be seen (left panel) that using the mid-latitude absorption cross sections for the tropics results in an overestimation of the effective transmission. As a result of the previous discussion only the spectral resolution of $\Delta \widetilde{v}=0.1 \mathrm{~cm}^{-1}$ is shown. The median $G_{50}(z)$ is up to $1.5 \%$, for shorter wavelengths (e.g., $\lambda_{0}=905 \mathrm{~nm}$, not shown) the overestimate is smaller and $G_{50}(z)$ is below $0.35 \%$. Inspection of the spectral absorption cross sections shows that for most of the wavelength grid points $\overline{\sigma_{\mathrm{w}}}$ is slightly larger under tropical conditions. Thus, absorption is underestimated when the values for the mid-latitudes are used. For reduced spectral resolutions $G_{50}(z)$ of up to $+4.5 \%$ can be found. In very few cases an underestimate of the transmission can occur, up to $-3.5 \%$. This confirms our previous conclusion that a reduced spectral resolution shall not be considered.

For the sake of completeness we have also investigated the inverse effect, i.e., the $\overline{\sigma_{\mathrm{w}}}(\lambda, z)$-table derived for the tropical site is used for the mid-latitude site in Munich. In this case a smaller systematic error of $G_{50}(z)$ is found: for $\lambda_{0}=912 \mathrm{~nm}$ it is below $0.5 \%$ (see Fig. 7, right panel), for shorter wavelength even smaller.

We conclude that $\overline{\sigma_{\mathrm{w}}}$ derived from a climatology of the same station should be used for the water vapor correction.
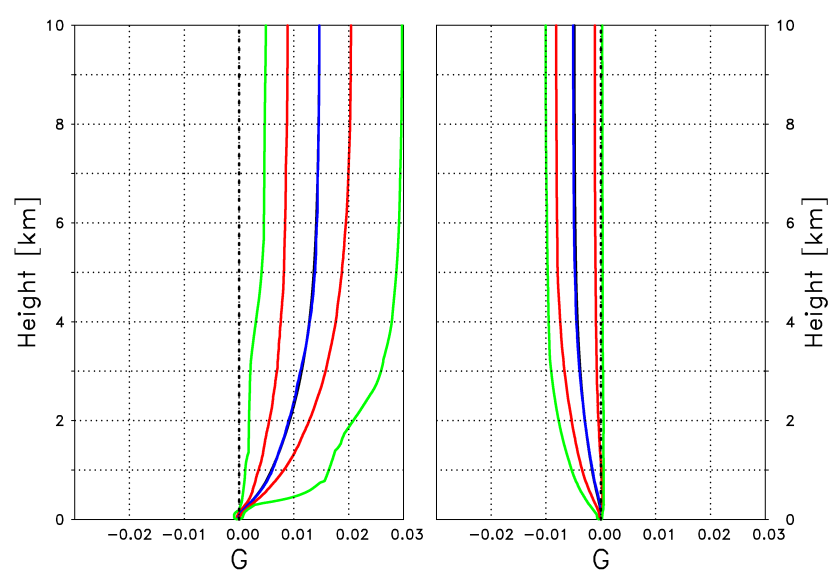

Figure 7. Deviation of the approximative squared transmissions $T_{\mathrm{w}, \mathrm{eff}, \mathrm{prx}}^{2}\left(t_{i}, z\right)$ from the reference case expressed in terms of the function $G\left(t_{i}, z\right)$ when $\overline{\sigma_{\mathrm{w}}}$ as derived for Oberschleißheim is used for Acapulco's water vapor distribution (left panel) and vice versa (right panel): average over all radiosonde ascents (black), $G_{50}(z)$ (blue), $G_{10}(z)$ and $G_{90}(z)$ percentile (red), and the minimum and maximum values (green). The emission spectrum of the laser diode is defined by $\lambda=912 \mathrm{~nm}$ and $\Delta \lambda=3.5 \mathrm{~nm}$. The spectral resolution is $\Delta \widetilde{v}=0.1 \mathrm{~cm}^{-1}$.

If this is, however, not available mean values from other stations can be applied as a systematic error, even in the extreme case discussed above, it is below $1-2 \%$ and thus seems to be acceptable.

\section{Examples of water vapor correction}

The main objective of this section is to show the magnitude of the error of the particle backscatter coefficient $\beta_{p}$ when the absorption of water vapor is not taken into account. Having water vapor absorption cross sections from WAPL and $n_{\mathrm{w}}$ from radiosonde ascents, $T_{\mathrm{w}, \mathrm{eff}}^{2}$ and "water vapor corrected" signals $P^{\prime}(z)$, see Eq. (9), can be calculated straightforwardly and a correction of ceilometer signals for water vapor absorption is possible.

To get realistic conclusions, it is reasonable to use measurements of a CL51 ceilometer. Measurements were available for a limited period of a few months in 2012 and took place at the roof platform of the Meteorological Institute of the Ludwig-Maximilians-Universität in Munich $\left(48.148^{\circ} \mathrm{N}\right.$ and $11.573^{\circ}$ E., $539 \mathrm{~m}$ a.m.s.l. - above mean sea level). Inspection of the CL51-data revealed that the signals exhibit a significant distortion in the free troposphere. As a consequence it was necessary to consider a "combination" of measurements and simulations in the following. Co-located and coincident measurements with a CHM15kx could be used for plausibility checks; a strict validation is in principle not possible as explained in Sect. 2.1. 


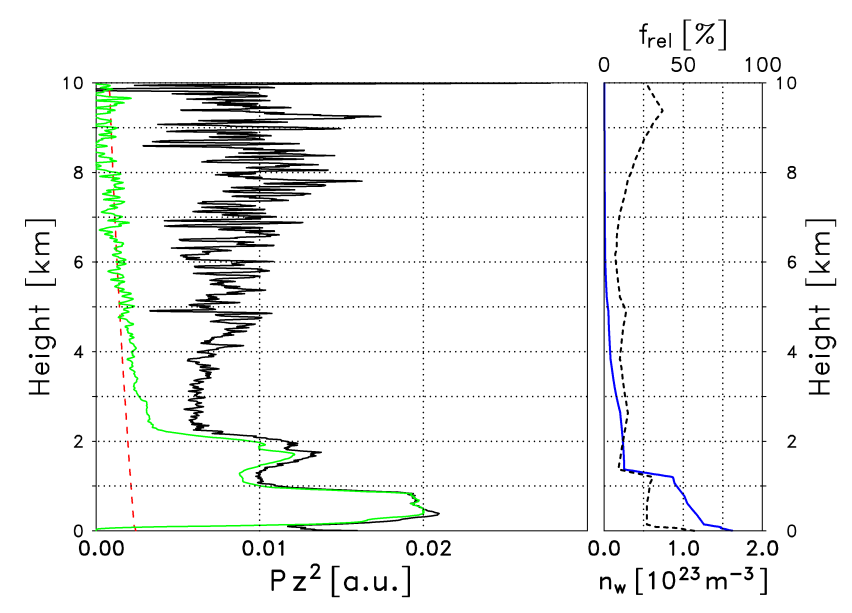

Figure 8. Left panel: range corrected signal $P z^{2}$ of the CL51 (black) of 17 March 2012, 02:00-04:00 UTC (Munich, Germany). The coincident profile of the CHM15kx is shown in green, the red dashed curve is a hypothetical Rayleigh-signal at $1064 \mathrm{~nm}$. All signals in arbitrary units. Right panel: profiles of relative humidity $f_{\text {rel }}$ (in $\%$, black) and water vapor number density $n_{\mathrm{W}}$ (in $10^{23} \mathrm{~m}^{-3}$, blue) from the radiosonde of Oberschleißheim.

\subsection{Case study}

For illustration, measurements of 17 March 2012 are shown in Fig. 8. In the left panel the range-corrected signal $P(z) z^{2}$ of the CL51 (black) averaged over $2 \mathrm{~h}$ (02:00-04:00 UTC) in arbitrary units is plotted. The mixing layer below $1 \mathrm{~km}$ and an elevated layer (between 1.3 and $2.2 \mathrm{~km}$ ) are clearly visible. For higher altitudes however the CL51 signal is quite noisy and does not show the expected slope of a "Rayleigh signal". The corresponding signal of the CHM15kx (green) is shown for comparison. Its shape follows the Rayleigh-signal much closer (red dashed line), thus it can be assumed to be more realistic. Note that the signals are scaled to match at $0.5 \mathrm{~km}$. In the right panel the profiles of the relative humidity $f_{\text {rel }}$ (in \%) and water vapor number concentration (in $10^{23} \mathrm{~m}^{-3}$ ) are shown to illustrate the vertical water vapor distribution $\left(w=6.0 \mathrm{~kg} \mathrm{~m}^{-2}\right)$. They are derived from the radiosonde of Oberschleißheim at 00:00 UTC.

From Fig. 8 it is clear that it is impossible to apply a Rayleigh-calibration to this CL51-signal and to retrieve $\beta_{p}$ by the backward algorithm (e.g., from $Z_{4}(z)$ and $N_{4}(z)$ ). In case that an absolute calibration is possible, i.e., $C_{L}$ is known, it will however be possible to derive $\beta_{p}$ by calculating $Z_{3}(z)$ and $N_{3}(z)$, but only for the altitude range not affected by the distortion, assumedly up to $2.2 \mathrm{~km}$.

As it is beyond the scope of this paper to discuss the quality of ceilometer data - according to our experience from other studies the signal-quality may change even between instruments of the same model - and how measurement errors possibly might be corrected, we decided to model realistic ceilometer signals (influenced by water vapor) based on
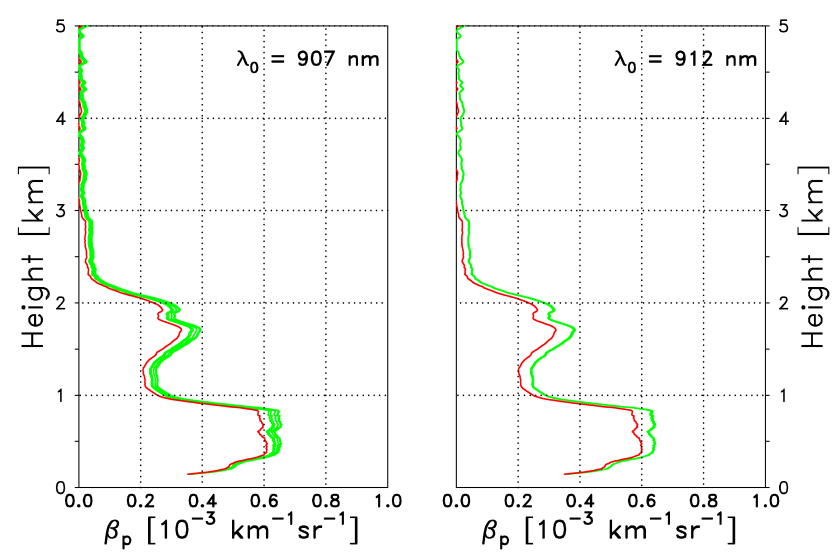

Figure 9. Retrieved particle backscatter coefficient at $\lambda_{0}=907 \mathrm{~nm}$ (left panel) and $912 \mathrm{~nm}$ (right panel) in $10^{-3} \mathrm{~km}^{-1} \mathrm{sr}^{-1}: \beta_{p}$ with (green) and $\beta_{p}^{*}$ without (red) water vapor correction. The water vapor distribution of 17 March 2012 is assumed.

the CHM15kx-measurements. So we can consider profiles of aerosol properties that are realistic for the site (note the very good qualitative agreement of the two profiles in the boundary layer), we can test the forward and the backward solution (in particular as we can set $\beta_{p}=0$ at a reference height), and the water vapor effect is not masked by measurement artifacts.

For the assessment of the influence of the water vapor absorption we at first retrieve $\beta_{p}$ at $1064 \mathrm{~nm}$ from the Jenoptik ceilometer and converted it to several wavelengths $\lambda_{0}$ around $910 \mathrm{~nm}$ by assuming an Angström exponent $\kappa=1.5$ and a wavelength-independent lidar ratio of $S_{p}=55 \mathrm{sr}$. The corresponding aerosol optical depth at $532 \mathrm{~nm}$ is $\tau_{p}=0.23$, which is somewhat above the annual average for Munich. All other relevant optical properties are derived from the radiosonde ascent. We assume that the lidar constant $C_{L}$ is known and that the emission spectrum of the ceilometer can be described by $\lambda_{0}$ and $\Delta \lambda=3.5 \mathrm{~nm}$. Finally, Eqs. (10) and (11) as discussed in Sect. 2.1 are used for the $\beta_{p}$-retrieval at $\lambda_{0}$.

Two representative results of the retrieved $\beta_{p}$-profile at two wavelengths $\lambda_{0}, 907 \mathrm{~nm}$ (Fig. 9, left panel) and $912 \mathrm{~nm}$ (right panel) assuming the water vapor distribution of 17 March 2012 are shown. Here, we have not considered the typical retrieval errors of the analytical solution (e.g., due to wrong estimates of $S_{p}$ and errors of $C_{L}$, see, e.g., the discussion in Wiegner et al. (2014) for the CHM15kx-ceilometer) as we want to elaborate the water vapor effect. The retrieved $\beta_{p}$ is determined with consideration of the water vapor absorption, i.e., $P^{\prime}(z)$ is used in $Z_{3}(z)$ and $N_{3}(z)$ and the correct $\lambda_{0}$. If we take into account, that under realistic conditions the assumption of $\lambda_{0}$ might be wrong by \pm 1 or $2 \mathrm{~nm}$, the resulting profiles (green curves) are moderately shifted (left panel) or virtually unchanged (right panel). This is a consequence of the different spectral dependence of water vapor absorption (compare Fig. 2) that is much stronger at $907 \mathrm{~nm}$. 


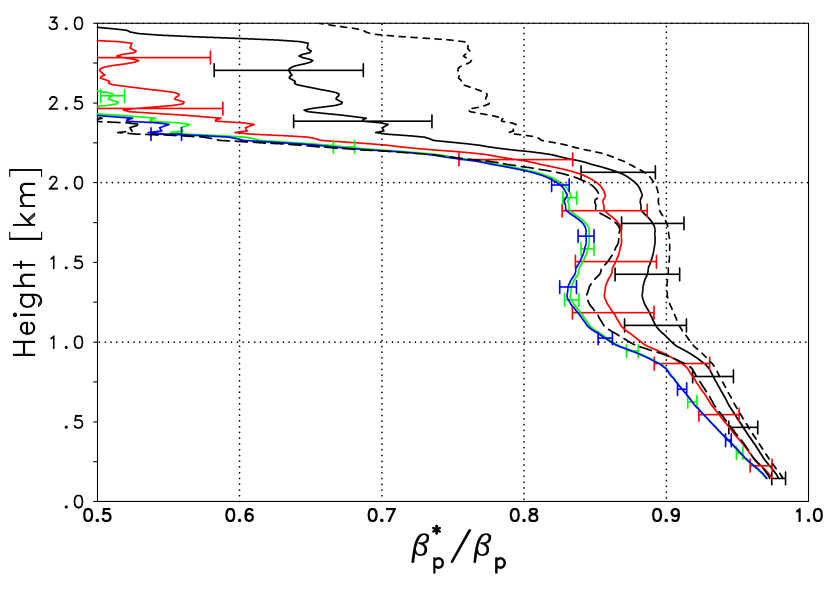

Figure 10. Ratio of the retrieved $\beta_{p}^{*}$ when water vapor absorption is ignored and the correct $\beta_{p}$ for different central wavelengths $\lambda_{0}$ of the emission spectrum: $905 \mathrm{~nm}$ (black), $908 \mathrm{~nm}$ (red), $911 \mathrm{~nm}$ (green), $914 \mathrm{~nm}$ (blue). The horizontal lines illustrate the uncertainties range due to wrong assumptions of $\lambda_{0}$ by $\pm 2 \mathrm{~nm}$. The long dashed line refers to the "clear" case, the short dashed line to the "turbid" case, both at $905 \mathrm{~nm}$ (conditions of 17 March 2012).

Thus, wrong assumptions of $\lambda_{0}$ have a larger influence at this wavelength. If the signal is treated as not being affected by water vapor, henceforward referred to as $\beta_{p}^{*}$, the aerosol backscatter coefficient is significantly lower (red curves): this effect is more pronounced at $912 \mathrm{~nm}$ as water vapor absorption is stronger at this wavelength, see again Fig. 2.

Additional insight in the effect of water vapor absorption on the retrieval is given in Fig. 10 where the ratio $\beta_{p}^{*} / \beta_{p}$ for four wavelengths $(905,908,911$, and $914 \mathrm{~nm}$, solid lines) is shown. It can be seen that the underestimate of the aerosol backscatter coefficient is increasing with height and amounts between 5 and $10 \%$ for the boundary layer, and between 10 and $20 \%$ for the elevated layer. In the free troposphere above $2.2 \mathrm{~km}$ the effect is even larger but less relevant as long as the low signal-to-noise ratio or signal distortion prohibits any aerosol retrieval. The horizontal lines indicate the uncertainties of the $\beta_{p}^{*} / \beta_{p}$-ratios if the above-mentioned uncertainty of $\lambda_{0}$ of $\pm 2 \mathrm{~nm}$ is taken into account. The underestimate is largest at 911 and $914 \mathrm{~nm}$, whereas at 908 and $905 \mathrm{~nm}$ the uncertainty is much larger. In other words, the correction of ceilometer signals is either small with a large uncertainty or large with a small uncertainty. Our simulations show that ignoring water vapor may lead to negative $\beta_{p}^{*}$ in the free troposphere. If not over-compensated by signal distortions as shown in Fig. 8, such unrealistic values can be used as a warning to treat the retrieved profile with caution.

If the same investigations are carried out for different aerosol loads - for this purpose we have multiplied the particle backscatter coefficient by a factor of 0.5 and 2.0, respectively - our results in general are confirmed. Under clear conditions ( $\tau_{p}=0.12$ at $532 \mathrm{~nm}$ ) the error of ignoring water vapor is somewhat larger, under turbid conditions $\left(\tau_{p}=0.44\right)$
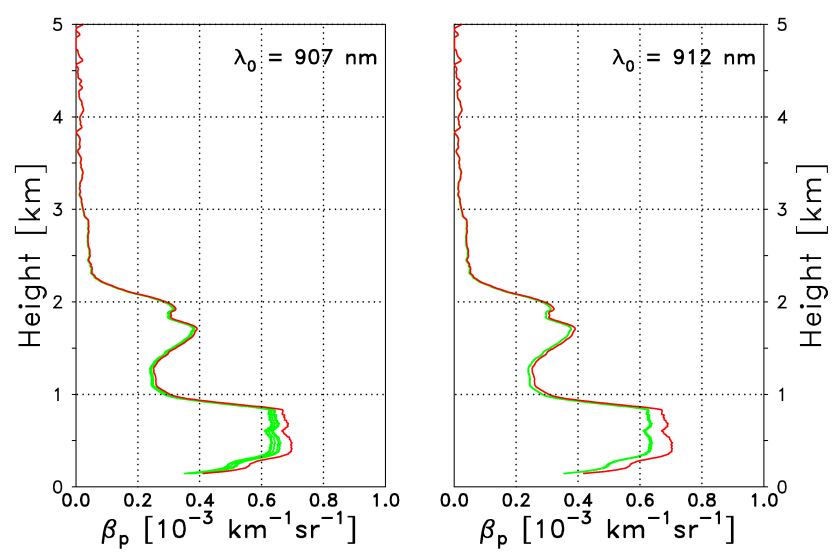

Figure 11. Same as Fig. 9 but application of the backward integration.

it is smaller. As an example the corresponding $\beta_{p}^{*} / \beta_{p}$-ratios have been added for $905 \mathrm{~nm}$ (Fig. 10): the short dashed line refers to the turbid case, the long dashed line to the clear case and reaches underestimates of approximately $15 \%$ in the elevated layer (approximately $22 \%$ at $914 \mathrm{~nm}$, not shown).

By using a "simulated measurement" we can also apply the backward integration with $Z_{4}$ and $N_{4}$ (Eqs. 12 and 13); under realistic conditions this will be restricted to temporal averages over typically two hours during nighttime, to cloudfree conditions and high-quality ceilometer data. We know from the simulation set-up (17 March 2012) that at an altitude of $8 \mathrm{~km}$ the aerosol backscatter coefficient is zero and water vapor absorption is negligible; thus the Rayleigh calibration can be applied. The resulting $\beta_{p}$-profiles are shown in Fig. 11: again $\lambda_{0}=907 \mathrm{~nm}$ (left panel) and $912 \mathrm{~nm}$ (right panel) are selected. It is obvious that ignoring the water vapor contribution (red curve) leads to a $\beta_{p}^{*}(z)$ that overestimates the true aerosol backscatter coefficient. The reason is that integration starts at a height that is strongly affected by the water vapor absorption of the lower layers and thus the reference value $\beta_{p}\left(z_{\text {ref }}\right)$ is underestimated. In the previous case (forward integration) integration starts at a height that is only little affected by the reduced transmission due to water vapor. With increasing height the effect of the absorption gets stronger leading to an underestimated $\beta_{p}^{*}$. As a consequence the accuracy of the retrievals for the elevated layer and the mixing layer are quite different for the two integration schemes (compare to Fig. 9). In case of the backward integration (see Fig. 11) the overestimate is only $5 \%$ in the elevated layer because the absorption between the reference height and the lower boundary of that layer is small due to the low water vapor concentration (see Fig. 8, right panel). Thus the water vapor transmission is comparable at both levels. In the mixing layer the overestimate of $\beta_{p}$ increases to around $10-15 \%$ because of the larger water vapor concentration in this layer leading to a more pronounced change of the water vapor transmission compared to the reference height. 


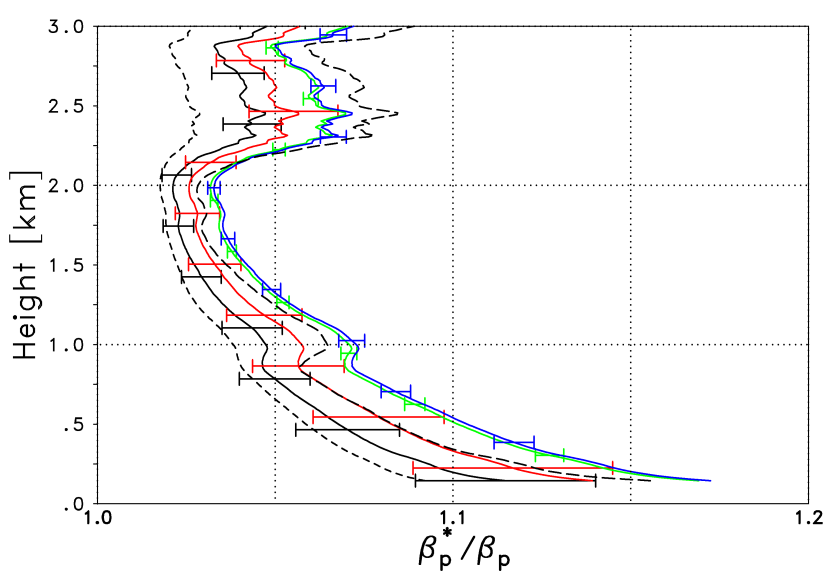

Figure 12. Same as Fig. 10 but application of the backward algorithm.

Corresponding to the above discussion we also show ratios of the two retrievals $\beta_{p}^{*} / \beta_{p}$ in case of the backward integration in Fig. 12. The same four wavelengths are selected. It is obvious that the neglect of water vapor will result in an overestimate. It can be seen that again at the retrieval it is better for the shorter wavelengths ( 905 and $908 \mathrm{~nm}$ ) but with quite a high uncertainty if the emitted wavelength is not known precisely. For the longer wavelengths the deviation from the correct retrieval is larger but not much affected by the $\lambda_{0^{-}}$ uncertainty. In most altitudes the systematic error of $\beta_{p}(z)$ is smaller if the backward integration is applied, only in the lowermost atmosphere the retrieval is worse. This might be an issue because these levels are of particular interest for air quality studies.

Analogously to the previous discussion we have included in Fig. 12 the $\beta_{p}^{*} / \beta_{p}$-ratios of the "clear" and the "turbid" case for one wavelength $(905 \mathrm{~nm})$. Similar to Fig. 10 it can be seen that the water vapor effect is somewhat larger under clear conditions (long dashed line in Fig. 12) and can exceed $10 \%$ in the lowermost troposphere.

\subsection{Estimate of a climatological average}

The case study discussed in the previous section - based on 17 March 2012 - was carried out for a relatively low water vapor content. However, as the water vapor distribution shows a large spatial and temporal variability, it is not justified to understand the results from a single case as a generally applicable number for the magnitude of the $\beta_{p}$-error when water vapor is ignored. In spite of the large variability, we try to give an order of magnitude of this error by considering the annual variability of the water vapor content at Munich and Acapulco. For this purpose we use the constant aerosol distribution as before but change $n_{\mathrm{w}}(z)$ according to the radiosonde ascents over 1 year. Figure 13 shows the annual mean of $\beta_{p}^{*} / \beta_{p}$ for 2013 for Oberschleißheim (solid lines) and Acapulco (dashed lines), note that the scale is different

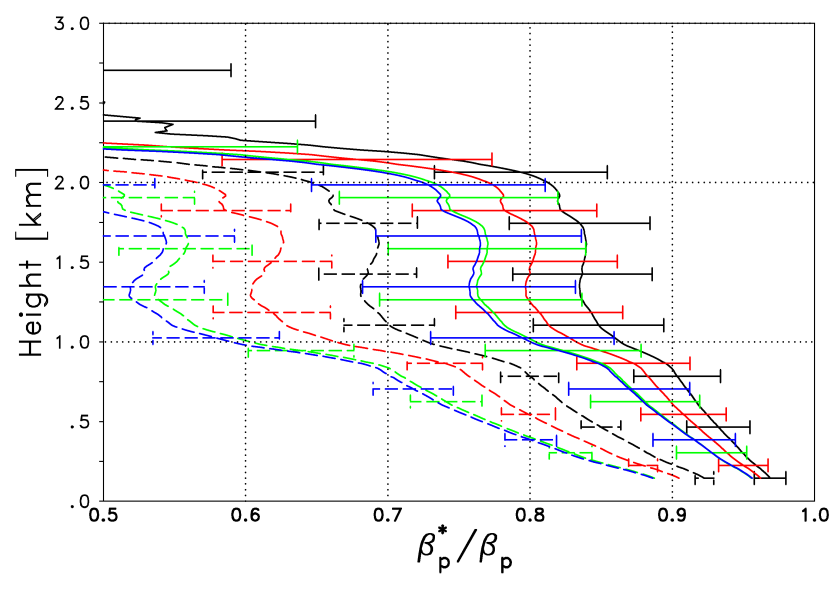

Figure 13. Ratio $\beta_{p}^{*} / \beta_{p}$ for four wavelengths $\lambda_{0}$, when the forward algorithm is applied: $905 \mathrm{~nm}$ (black), $908 \mathrm{~nm}$ (red), $911 \mathrm{~nm}$ (green), $914 \mathrm{~nm}$ (blue). The solid and dashed lines are the annual averages (year 2013) for Oberschleißheim and Acapulco, respectively. The horizontal lines indicate the standard deviation.

to Fig. 10. It can be seen from the standard deviation (horizontal lines) that the annual variability is quite high. As a consequence only orders of magnitude of the error are given below to stress the necessity of a correction for water vapor absorption in each individual case. Application of the forward algorithm results in an underestimate between 5 and $25 \%$ for the mid-latitude site and at least $10 \%$ and up to a factor of 2 for the tropical site. The corresponding results for the same year applying the backward algorithm are shown in Fig. 14. As expected from the above case study the errors are smaller for the elevated layer and slightly larger in the mixing layer. The mean overestimate of $\beta_{p}$ in the mixing layer is in the order of $20 \%$ (mid-latitudes) and $35 \%$ (tropics).

These results confirm that it is not possible to find one generally applicable value for the $\beta_{p}$-error if water vapor absorption is neglected.

\section{Summary and conclusions}

If ceilometers, emitting radiation in the spectral range around 905-910 nm, shall be used to derive aerosol optical properties in a quantitative way, the signal must be corrected for water vapor. In this paper a methodology named WAPL is introduced that does not require time-consuming absorption calculations with high spectral resolution but relies on tabulated water vapor absorption cross sections. It has been shown that the inherent error of this approximation is in the order of only $0.3 \%$ and thus virtually negligible. Furthermore, it has been demonstrated that these tabulated values need not necessarily be determined for the site of the ceilometer; this might allow to use one data base for a group of ceilometers in similar environments (climate zone, altitude). The corresponding error is expected to be below $1 \%$. 


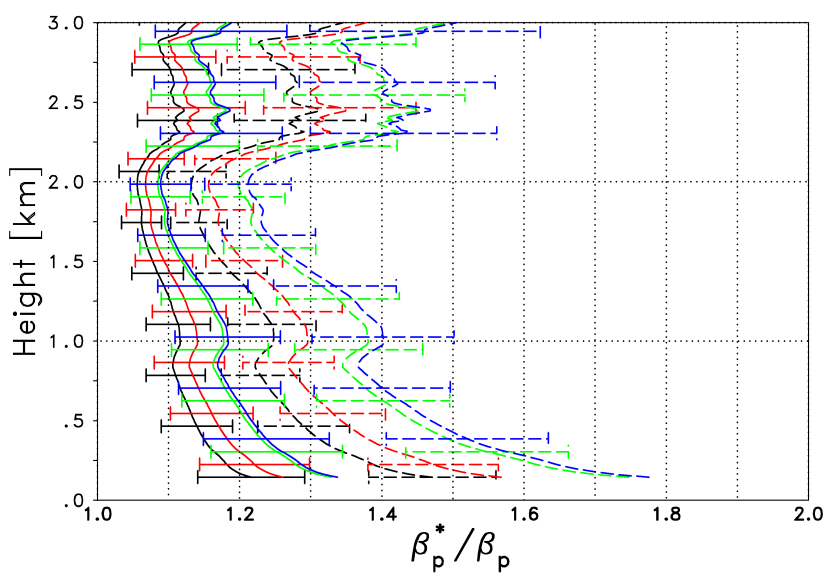

Figure 14. Same as Fig. 13 but application of the backward algorithm.

To apply WAPL, the emitted spectrum of the laser diode should be known or at least a reasonable estimate must be available. It has been shown that the water vapor correction is more accurate at wavelengths around $910 \mathrm{~nm}$ than around $905 \mathrm{~nm}$. The uncertainties of the water vapor correction are, however, significantly smaller than the error if water vapor is totally ignored as has usually been the case in the past. To benefit from WAPL as much as possible the laser spectrum should be provided by the manufacturer; if the laser source is not temperature-stabilized the emitted wavelengths should be specified as a function of temperature. In this paper we have assumed a Gaussian curve with a FWHM $\Delta \lambda$ of 3-4 nm.

Due to the large temporal and spatial variability of the water vapor distribution it is not possible to give a unique number of the error when water vapor absorption is not taken into account. To get an indication of its magnitude we have studied a number of simulations based on a realistic aerosol distribution in Munich and water vapor distributions over 1 year in Munich and a tropical site. It was found that the systematic error of the aerosol backscatter coefficient $\beta_{p}$ is in the order of $10 \%$ for mid-latitude meteorological conditions but can reach $50 \%$ and more in the tropics, and thus can exceed the errors of the Klett retrieval. The magnitude of the error furthermore depends on the inversion scheme (forward or backward integration). It should be kept in mind that other error sources significantly contribute to the overall error of $\beta_{p}$, in particular the accuracy of the ceilometer signal itself, that might prevent a quantitative evaluation of the measurement. We want to emphasize that a strict validation of WAPL is not possible at the moment due to a lack of information that complicates the extrapolation from a wavelength not influenced by water vapor absorption to $905-910 \mathrm{~nm}$. For this purpose the dedicated validation campaign CeiLinEx was initiated. It is currently (September 2015) ongoing in Lindenberg, Germany, with the participation of different ceilometer models, and the implementation of an advanced lidar system and pho- tometers to characterize the vertical aerosol distribution. For validation, a careful selection of adequate meteorological situations is important, i.e., conditions with aerosol properties changing with height should be avoided. But for physical reasons it is certainly useful to apply the water vapor correction even if the strict validation is still missing; it will help to avoid a significant systematic error of the retrieved $\beta_{p}$.

Finally we again want to emphasize that ceilometers were primarily designed for the determination of cloud heights, and that attempts to retrieve aerosol properties only came up very recently. We expect that in the near future the number of unattended and automated ceilometers and backscatter lidars will further grow, and that the hardware and proprietary software might be adapted "towards aerosols". As a consequence it can be anticipated that a significant data set of signals at wavelengths around $910 \mathrm{~nm}$ will be available for aerosol remote sensing. Then, water vapor correction must be an indispensable part of any data evaluation scheme.

Acknowledgements. We gratefully acknowledge Klaus Schäfer and Carsten Jahn (Karlsruher Institut für Technologie (KIT) IMK-IFU) for the provision of the CL51 ceilometer during several months in 2012. The radiosonde data were downloaded from http://weather.uwyo.edu/upperair/sounding.html of the University of Wyoming, College of Engineering, Department of Atmospheric Science. Parts of the work underlying this publication were funded by LMU Munich's Institutional Strategy "LMUexcellent" within the framework of the German Excellence Initiative.

Edited by: U. Wandinger

\section{References}

Anderson, G. P., Clough, S. A., Kneizys, F. X., Chetwynd, J. H., and Shettle, E. P.: AFGL Atmospheric Constituent Profiles (0120 km), AFGL-TR-86-0110, Hanscom AFB, MA 01736, USA, 1986.

Bodhaine, B. A., Wood, N. B., Dutton, E. G., and Slusser, J. R.: On Rayleigh Optical Depth Calculations, J. Atmos. Ocean. Tech., 16, 1854-1861, 1999.

Buehler, S. A., Eriksson, P., Kuhn, T., von Engeln, A., and Verdes, C.: ARTS, the atmospheric radiative transfer simulator, J. Quant. Spectrosc. Ra., 91, 65-93, 2005.

Clough, S., Shephard, M., Mlawer, E., Delamere, J., Iacono, M., Cady-Pereira, K., Boukabara, S., and Brown, P.: Atmospheric radiative transfer modeling: a summary of the AER codes, J. Quant. Spectrosc. Ra., 91, 233-244, doi:10.1016/j.jqsrt.2004.05.058, 2005.

Dirksen, R. J., Sommer, M., Immler, F. J., Hurst, D. F., Kivi, R., and Vömel, H.: Reference quality upper-air measurements: GRUAN data processing for the Vaisala RS92 radiosonde, Atmos. Meas. Tech., 7, 4463-4490, doi:10.5194/amt-7-4463-2014, 2014.

Emeis, S., Jahn, C., Münkel, C., Münsterer, C., and Schäfer, K.: Multiple atmospheric layering and mixing-layer height in the Inn valley observed by remote sensing, Meteorol. Z., 16, 415-424, doi:10.1127/0941-2948/2007/0203, 2007. 
Emeis, S., Forkel, R., Junkermann, W., Schäfer, K., Flentje, H., Gilge, S., Fricke, W., Wiegner, M., Freudenthaler, V., Groß, S., Ries, L., Meinhardt, F., Birmili, W., Münkel, C., Obleitner, F., and Suppan, P.: Measurement and simulation of the 16/17 April 2010 Eyjafjallajökull volcanic ash layer dispersion in the northern Alpine region, Atmos. Chem. Phys., 11, 26892701, doi:10.5194/acp-11-2689-2011, 2011.

Eresmaa, N., Karppinen, A., Joffre, S. M., Räsänen, J., and Talvitie, H.: Mixing height determination by ceilometer, Atmos. Chem. Phys., 6, 1485-1493, doi:10.5194/acp-6-1485-2006, 2006.

Fernald, F. G., Herman, B. M., and Reagan, J. A.: Determination of aerosol height distributions by lidar, J. Appl. Meteorol., 11, 482-489, 1972.

Gasteiger, J., Emde, C., Mayer, B., Buras, R., Buehler, S. A., and Lemke, O.: Representative wavelengths absorption parameterization applied to satellite channels and spectral bands, J. Quant. Spectrosc. Ra., 148, 99-115, doi:10.1016/j.jqsrt.2014.06.024, 2014.

Haeffelin, M., Angelini, F., Morille, Y., Martucci, G., Frey, S., Gobbi, G. P., Lolli, S., O’Dowd, C. D., Sauvage, L., XuerefRémy, I., Wastine, B., and Feis, D. G.: Evaluation of MixingHeight Retrievals from Automatic Profiling Lidars and Ceilometers in View of Future Integrated Networks in Europe, Bound.Lay. Meteorol., 143, 49-75, doi:10.1007/s10546-011-9643-z, 2011.

Hirsikko, A., O'Connor, E. J., Komppula, M., Korhonen, K., Pfüller, A., Giannakaki, E., Wood, C. R., Bauer-Pfundstein, M., Poikonen, A., Karppinen, T., Lonka, H., Kurri, M., Heinonen, J., Moisseev, D., Asmi, E., Aaltonen, V., Nordbo, A., Rodriguez, E., Lihavainen, H., Laaksonen, A., Lehtinen, K. E. J., Laurila, T., Petäjä, T., Kulmala, M., and Viisanen, Y.: Observing wind, aerosol particles, cloud and precipitation: Finland's new groundbased remote-sensing network, Atmos. Meas. Tech., 7, 13511375, doi:10.5194/amt-7-1351-2014, 2014.

Jin, Y., Kai, K., Kawai, K., Nagai, T., Sakai, T., Yamazaki, A., Uchiyama, A., Batdorj, D., Sugimoto, N., and Nishizawa, T.: Ceilometer calibration for retrieval of aerosol optical properties, J. Quant. Spectrosc. Ra., 153, 49-56, doi:10.1016/j.jqst.2014.10.009, 2015.

Klett, J. D.: Stable analytical inversion solution for processing lidar returns, Appl. Optics, 20, 211-220, 1981.

Leroyer, S., Bélair, S., Husain, S.-Z., and Mailhot, J.: Subkilometer Numerical Weather Prediction in an Urban Coastal Area: A Case Study over the Vancouver Metropolitan Area. J. Appl. Meteorol. Clim., 53, 1433-1453 doi:10.1175/JAMC-D-13-0202.1, 2013.

Madonna, F., Amato, F., Vande Hey, J., and Pappalardo, G.: Ceilometer aerosol profiling vs. Raman lidar in the frame of INTERACT campaign of ACTRIS, Atmos. Meas. Tech., 8, 22072223, doi:10.5194/amt-8-2207-2015, 2015.

Markowicz, K. M., Flatau, P. J., Kardas, A. E., Remiszewska, J., Stelmaszczyk, K., and Woeste, L.: Ceilometer Retrieval of the Boundary Layer Vertical Aerosol Extinction Structure, J. Atmos. Ocean. Tech., 25, 928-944, 2008.
Martucci, G., Milroy, C., and O'Dowd, C. D.: Detection of cloudbase height using Jenoptik CHM15K and Vaisala CL31 ceilometers, J. Atmos. Ocean. Tech., 27, 305-318, 2010.

McKendry, I. G., van der Kamp, D., Strawbridge, K. B., Christen, A., and Crawford, B.: Simultaneous observations of boundary-layer aerosol layers with CL31 ceilometer and 1064/532 nm lidar, Atmos. Environ., 43, 5847-5852, doi:10.1016/j.atmosenv.2009.07.063, 2009.

Miloshevich, L. M., Vömel, H., Whiteman, D. N., and Leblanc, T.: Accuracy assessment and correction of Vaisala RS92 radiosonde water vapor measurements, J. Geophys. Res., 114, D11305, doi:10.1029/2008JD011565, 2009.

Münkel, C., Eresmaa, N., Räsänen, J., and Karppinen, A.: Retrieval of mixing height and dust concentration with lidar ceilometer, Bound.-Lay. Meteorol., 124, 117-128, 2007.

Rothman, L. S., Jacquemart, D., Barbe, A., Chris Benner, D., Birk, M., Brown, L., Carleer, M., Chackerian Jr, C., Chance, K., Coudert, L., Dana, V., Devi, V. M., Flaud, J.-M., Gamache, R. R., Goldman, A., Hartmann, J. M., Jucks, K. W., Maki, A. G., Mandin, J.-Y., Massie, S. T., Orphal, J., Perrin, A., Rinsland, C. P., Smith, M. A. H., Tennyson, J., Tolchenov, R. N., Toth, R. A., Vander Auwera, J., Varanasi, P., and Wagner, G.: The HITRAN 2004 molecular spectroscopic database, J. Quant. Spectrosc. Ra., 96, 139-204, doi:10.1016/j.jqsrt.2004.10.008, 2005.

Sundström, A. M., Nousiainen, T., and Petäjä, T.: On the Quantitative Low-Level Aerosol Measurements Using Ceilometer-Type Lidar, J. Atmos. Ocean. Tech., 26, 23402352, doi:10.1175/2009JTECHA1252.1, 2009.

Tsaknakis, G., Papayannis, A., Kokkalis, P., Amiridis, V., Kambezidis, H. D., Mamouri, R. E., Georgoussis, G., and Avdikos, G.: Inter-comparison of lidar and ceilometer retrievals for aerosol and Planetary Boundary Layer profiling over Athens, Greece, Atmos. Meas. Tech., 4, 1261-1273, doi:10.5194/amt-4-1261-2011, 2011.

Wiegner, M. and Geiß, A.: Aerosol profiling with the Jenoptik ceilometer CHM15kx, Atmos. Meas. Tech., 5, 1953-1964, doi:10.5194/amt-5-1953-2012, 2012.

Wiegner, M., Gasteiger J., Groß S., Schnell F., Freudenthaler, V., and Forkel, R.: Characterization of the Eyjafjallajökull ashplume: Potential of lidar remote sensing, Phys. Chem. Earth, 4546, 79-86, doi:10.1016/j.pce.2011.01.006, 2012.

Wiegner, M., Madonna, F., Binietoglou, I., Forkel, R., Gasteiger, J., Geiß, A., Pappalardo, G., Schäfer, K., and Thomas, W.: What is the benefit of ceilometers for aerosol remote sensing? An answer from EARLINET, Atmos. Meas. Tech., 7, 1979-1997, doi:10.5194/amt-7-1979-2014, 2014.

Young, J. S. and Whiteman, C. D.: Laser Ceilometer Investigation of Persistent Wintertime Cold-Air Pools in Utah's Salt Lake Valley, J. Appl. Meteorol. Clim., 54, 752-765, doi:10.1175/JAMCD-14-0115.1, 2015. 